\title{
Fitch's Paradox of Knowability and the Knower Paradox: Against a Proposed Dialetheist Unified Solution
}

\author{
RICARDO SANTOS*
}

\begin{abstract}
After introducing Fitch's paradox of knowability and the knower paradox, the paper critically discusses the dialetheist unified solution to both problems that Beall and Priest have proposed. It is first argued that the dialetheist approach to the knower paradox can withstand the main objections against it, these being that the approach entails an understanding of negation that is intolerably weak (allowing one to stay in agreement with something that one negates) and that it commits dialetheists to jointly accept and reject the same thing. The lesson of the knower paradox, according to dialetheism, is that human knowledge is inconsistent. The paper also argues that this inconsistency has not been shown by dialetheists to be wide enough in its scope to justify their approach to Fitch's problem. The connection between the two problems is superficial and therefore the proposed unified solution fails.
\end{abstract}

Keywords: dialetheism, epistemic norms, Fitch's paradox, inconsistent knowledge, knower paradox, negation, rejection.

\section{Introduction}

$\mathrm{F}$

itch's paradox of knowability is an argument intended to prove that if every truth is knowable then every truth is actually known. Since it's obvious that humans are not omniscient beings, it seems that one should conclude from it that some truths are unknowable - that there are necessary limits to human knowledge. Perhaps that is indeed true. Some philosophers, however, doubt it. And others think that, even if there are truths beyond the reach of human knowledge, that is a very substantial issue that we shouldn't be able to establish by so meager means as those used by Fitch's argument. One other problem raised in contemporary philosophy of logic is the so-called knower paradox, a member of the daunting family of paradoxes of self-reference. In it we are called to consider a sentence saying of itself that is not known. A simple argument, very similar to the much more familiar liar paradox, leads to the contra-

* $\quad$ Universidade de Lisboa, Faculdade de Letras, LanCog Research Group.

$\triangle$ santos.ricardo@campus.ul.pt 
dictory conclusion that this sentence is both known and not known. Paradoxes like this, we have learned to appreciate, are extremely difficult to deal with. They may require radical departures from common sense and perhaps revisions of classical logic. Dialetheism is one such departure: it claims that some contradictions are true and that the paradoxes of self-reference are exactly what they seem to be, viz. sound arguments with true contradictory conclusions. Dialetheism urges us to accept them and to subscribe to a paraconsistent logic. Renowned dialetheists ${ }^{1}$ have recently proposed that, by endorsing dialetheism, one can also discover a tight connection between Fitch's paradox and the knower paradox and provide a unified solution to both. Roughly, such solution says that both paradoxes are fundamentally concerned with the inconsistency of knowledge, that is, with there being truths that can be both known and not known: Fitch's paradox shows (from the principle that every truth is knowable) that human knowledge is possibly inconsistent and the knower paradox confirms (from very basic principles about knowledge) that it actually is inconsistent. In this paper I critically examine this proposal.

I will proceed as follows. In sections 2 and 3, I briefly present Fitch's paradox and the knower paradox. In section 4, the dialetheist approach to both paradoxes is articulated (which will require a dialetheist repair of Fitch's argument) and the unified solution is described. The next sections critically discuss three main objections to the proposed solution. Section 5 considers whether the dialetheist account of negation is tenable or intolerably weak. Section 6 discusses a very challenging objection to the dialetheist approach to the knower paradox, stemming from an epistemic norm, which arguably regulates the relation between acceptance and knowledge. Section 7 focuses on the dialetheist approach to Fitch's paradox, discussing how wide should the scope of inconsistent knowledge be for that approach to be plausible. Based on these discussions, I conclude that the proposed unified solution fails. While the approach to the knower paradox is defensible, the connection it makes with Fitch's problem is superficial and accidental.

1. JC Beall, "Fitch's Proof, Verificationism, and the Knower Paradox," Australasian Journal of Philosophy 78, no. 2 (2000): 241-247 and Graham Priest, "Beyond the Limits of Knowledge," in New Essays on the Knowability Paradox, ed. Joe Salerno (Oxford University Press, 2009), 93-104.

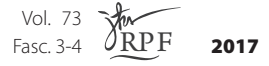




\section{Fitch's Paradox of Knowability}

We surely do not know everything, but some philosophers have thought, based on various reasons, that every truth can be known in principle. An interesting argument first published by Frederic Fitch ${ }^{2}$, but most likely due to Alonzo $\mathrm{Church}^{3}$, purports to show that those philosophers are wrong and that there are necessary limits to what can be known by non-omniscient beings like us. In outline, the argument points out that, for every truth that is not known (by anyone at any time), there is one related truth that cannot be known. Why is that so? Simply because an unknown truth cannot be known to be an unknown truth; otherwise, it would be known and unknown at the same time.

Fitch's argument relies on two basic principles concerning knowledge. First, that knowledge is factive: only truths can be known. Second, that knowledge distributes over conjunction: if a conjunction is known, then both conjuncts must be known. The following is a standard presentation of the argument, using ' $K$ ' as a one-place operator to be read as 'It is known (by someone at some time) that' and $\square$ and $\nabla$ as modal operators for logical necessity and possibility, respectively:

(1) Some truths are not known: $\exists p(p \wedge \neg K p)$

(2) Let $q$ be one of those unknown truths: $q \wedge \neg K q$

(3) Assume, for reductio, that every truth is knowable: $\forall p(p \rightarrow \diamond K p)$

(4) Instantiate the knowability principle, 3 , with the special case given at 2 : $(q \wedge \neg K q) \rightarrow \diamond K(q \wedge \neg K q)$

(5) $\diamond K(q \wedge \neg K q)$, from 2 and 4, by modus ponens.

(6) Assume, for reductio, that $K(q \wedge \neg K q)$.

(7) $K q \wedge K \neg K q$, from 6, by distribution of $K$.

(8) $K q \wedge \neg K q$, from 7 , by factivity of $K$. Contradiction!

(9) $\neg K(q \wedge \neg K q)$, from 6 and 8 , by reductio.

(10) $\square \neg K(q \wedge \neg K q)$, from 9 , by necessitation of theorems.

(11) $\neg \diamond K(q \wedge \neg K q)$, from 10 , by the equivalence of $\square \neg$ with $\neg \oslash$.

2. In Frederic Fitch, "A Logical Analysis of Some Value Concepts," Journal of Symbolic Logic 28, no. 2 (1963): 135-142.

3. See Joe Salerno, "Knowability Noir: 1945-1963," in New Essays on the Knowability Paradox, ed. Joe Salerno (Oxford University Press, 2009), 34-37.

$$
\begin{aligned}
\text { Vol. } 73 & \text { Fasc. 3-4 } \\
\text { RPF } & 2017
\end{aligned}
$$


(12) 11 contradicts 5.

(13) Not every truth is knowable: $\exists p(p \wedge \neg \nabla K p)$, from 3 and 12, by reductio.

(14) If some truths are not known, then some truths are unknowable, from 1 and 13 , by introduction of the conditional.

There has been an intense debate regarding this argument, mainly between realists and anti-realists about truth (the latter subscribing to the view that there is no truth independently of our recognition of it). Many anti-realists (and also verificationists, who endorse the thesis that a sentence is meaningful only if it is in principle verifiable) think that Fitch's argument forces us to find a more refined way of stating the knowability principle, but not to abandon it. Many realists, on the other hand, welcome the argument, as evidence of a gap between human knowledge and reality which should not be surprising, given that truth is not an epistemic concept and what is true depends very little on us humans. In this paper, I will only consider the approach to Fitch's argument from a dialetheist point of view.

As I have present it above, Fitch's argument uses twice a classical form of reductio that is unacceptable for dialetheists. On their view, if something leads to a contradiction, that by itself does not prove that it is false, since some contradictions are true. In the above derivation, the contradictions we arrived at were: $K q \wedge \neg K q$, at line 8, and $\diamond K(q \wedge \neg K q) \wedge$ $\neg \nabla K(q \wedge \neg K q)$, at line 12. But is there any specific and independent reason to think that these contradictions may be true? What could motivate one to take a dialetheist approach to this argument? According to Beall and Priest, we have indeed independent reasons to think that knowledge is inconsistent, which means that, for some $p$, it is the case that $K p$ and it is also the case that $\neg K p$. Those reasons come from another paradox, the knower, to which I now turn.

\section{The Knower Paradox}

Discussions of the liar paradox, which concerns a sentence saying of itself that it is not true, have been prominent in contemporary philosophy of logic - and a great variety of theories have been worked out trying to account for the problem. In comparison, much less attention has been devoted to the (structurally very similar) knower paradox, due to Kaplan and Montague, which concerns a sentence saying of itself that it is not

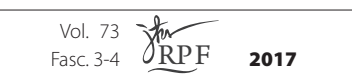


known. ${ }^{4}$ In this case, the argument starts out by considering a sentence $k$ identical with ' $k$ is not known'. The first part of the argument relies on the factivity of knowledge and proves that $k$ is not known - by showing that if $k$ is known, then $k$ is true and so it is not known, because that is exactly what it says. The second part of the argument relies on the principle that proof produces knowledge: having proved that $k$ is not known (on the first part), we have thereby proved $k$, so we now know $k$, hence $k$ is known. A bit more formally:

(1) $k=$ ' $k$ is not known'

(2) $k$ is known

(3) $k$ is not known

(4) If $k$ is known, then $k$ is not known

(5) $k$ is not known

(6) $k$ is proved

(7) $k$ is known

(8) $k$ is known and $k$ is not known
Definition

Assumption

From 2, by the factivity of knowledge

From 2 and 3, discharging the assumption

From 4, based on no assumptions

Lines 1 to 5

From 6 , by the principle that proof produces knowledge

From 5 and 7

Given the great similarity between the two, it is natural that the main kinds of solution that have been proposed for the liar paradox should also be available for the knower paradox. One of those solutions is dialetheism, based on a paraconsistent logic. Dialetheism sees the knower paradox as a sound argument, with a true conclusion. According to it, the knower sentence, $k$, is both known and not known. ${ }^{5}$ Moreover, dialetheists claim that, once one accepts this fact, one should take a fresh look at Fitch's argument against the knowability principle.

Before we move forward, a clarification is in order. Although it allows that some contradictions may be true, in a paraconsistent logic such as Priest's Logic of Paradox $(L P)^{6}$ the law $\neg(p \wedge \neg p)$ holds, as does also its

4. David Kaplan and Richard Montague, "A Paradox Regained," Notre Dame Journal of Formal Logic 1, no. 3 (1960): 79-90.

5. See also Graham Priest, Beyond the Limits of Thought (Oxford: Clarendon Press, 2002), 144-145.

6. See Graham Priest, An Introduction to Non-Classical Logic, $2^{\text {nd }}$ edition (Cambridge University Press, 2008), chapter 7.

\begin{tabular}{|c|c|c|}
\hline Fasc. 3-4 & $\gamma_{\mathrm{RPF}}$ & 2017 \\
\hline
\end{tabular}


necessitation, $\square \neg(p \wedge \neg p)$, which is equivalent to $\neg \diamond(p \wedge \neg p)$. Thus, $\neg \diamond(K p$ $\wedge \neg K p)$ is valid in $L P$ : it is impossible that $p$ be both known and not known, for every $p$. What the knower paradox allegedly shows is that, for some $p$, what is impossible is also possible. ${ }^{7}$ According to dialetheism, in the case of the knower sentence, $k$, we have both $\diamond(K k \wedge \neg K k)$ and $\neg \diamond(K k \wedge \neg K k){ }^{8}$

\section{A Unified Solution?}

Following what Routley suggested ${ }^{9}$, both Beall and Priest have claimed that there is a tight connection between Fitch's argument and the knower paradox, consisting in the fact that the knower gives us an actual instance of what Fitch showed only to be possible.

Usually, Fitch's argument is presented, as I did above, as purporting to prove that, if we are not ominiscient, then there are unknowable truths and so the knowability principle is false. That version of the argument, however, employs a classical rule of reductio that is not valid in a paraconsistent logic such as Priest's $L P$. Repairing it in accordance with $L P$, the most one can get is an argument showing that non-omniscience and the knowability principle, together, entail that, for some proposition, it is possible that it be both known and not known. The following is a paraconsistently valid version of Fitch's argument:

(1) Some truths are not known: $\exists p(p \wedge \neg K p)$

(2) Let $q$ be one of those unknown truths: $q \wedge \neg K q$

(3) Every truth is knowable: $\forall p(p \rightarrow \diamond K p)$

(4) Instantiate the knowability principle, 3 , with the special case given at 2 : $(q \wedge \neg K q) \rightarrow \diamond K(q \wedge \neg K q)$

7. This is an example of dialetheists' weak use of negation, which I will discuss on section 5 .

8. As the attentive reader has surely noticed, in the last two sections, I have been oscillating between using 'is known' as an operator and using it as a predicate. This makes no real difference. Where $<s>$ is a name of a sentence $s$, one can just take ' $<s>$ is known' as an abbreviation of 'It is known that $s$ ', which in turn is an abbreviation of 'Someone at some time knows that $s$ '. Whenever I talk of knowing a sentence, it should be understood as a loose way of saying that the content of the sentence (the proposition is expresses) is known.

9. In Richard Routley, "Necessary Limits to Knowledge: Unknowable Truths", in Essays in Scientific Philosophy. Dedicated to Paul Weingartner, eds. M. Edgar, N. Otto and Z. Gerhard (Bad Reichenhall: Comes Verlag, 1981), 112, n. 26.

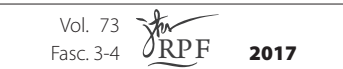


(5) $\diamond K(q \wedge \neg K q)$, from 2 and 4 , by modus ponens.

(6) Suppose that $K(q \wedge \neg K q)$

(7) $K q \wedge K \neg K q$, from 6, by distribution of $K$.

(8) $K q \wedge \neg K q$, from 7, by factivity of $K$.

(9) $\diamond(K q \wedge \neg K q)$, from 5 and 6-7-8, by the rule, valid in $L P$, 'From $\diamond A$ and $A$ implies $B$, derive $\diamond B^{\prime} .^{10}$

Instead of a refutation of the knowability principle, what we have, in a paraconsistent logic, is an argument showing that this principle entails the possibility of some proposition being both known and not known. Of course, classical logicians and supporters of Fitch's original argument take this consequence to be unacceptable and they may think of it as giving sufficient reason to deny the knowability principle. At this point, proponents of dialetheism claim that the conclusion one has arrived at, surprising as it may be, is actually proved to be true by the knower paradox. In fact, if taken at face value, the knower paradox gives us a proof of a proposition stating of itself that it is not known: that proposition is not known, because we have proved it to be so, and it is also known, because we are able to prove it. Thus the knower paradox provides us with a particular and actual witness of the general possibility stated by the repaired version of Fitch's argument. Since knowledge is inconsistent, as shown by the knower paradox, Fitch's argument is not efficacious against the knowability principle. The knowability principle indeed entails the possibility of there being inconsistent knowledge, but that consequence is known to be unproblematic.

\section{First Objection: Dialetheic Negation}

In the previous section, I have briefly presented a dialetheist proposal of a unified solution to both the knower paradox and Fitch's paradox of knowability. I turn now to a critical discussion of what in my view are the strongest objections such proposal has to face. Let us start by considering an objection to one central feature of dialetheism, which is its peculiar understanding of negation. The objection says that, by holding that, for some sentences $A$, both $A$ and $\neg A$ are true, dialetheism violates the

10. Lines 6 to 8 of the derivation show that $K(q \wedge \neg K q)$ implies $K q \wedge \neg K q$. If the first is true in some possible world $w$, the second is true in $w$ as well.

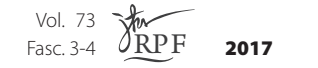


traditional conception of negation, according to which the negation of a sentence is true if and only if that sentence fails to be true. Negation as dialetheists understand it is thus too weak, as shown by the fact that, according to its principles, someone may assert $\neg A$ while at the same time agreeing with those who assert $A$. That, the objector claims, is not real negation.

This objection raises an important issue and it carries considerable weight, but dialetheists like Priest have a well worked-out answer to give ${ }^{11}$. There is a lot about negation that dialetheists and classical logicians can still agree on (e.g., that negation reverses truth value, that a sentence and its negation are contradictories, that at least one of them is true, etc.); and where they diverge - concerning the behaviour of negation in paradoxical situations -, it is not immediately obvious who gets it right. Priest claims that negation is an operator that has the essential function of forming the contradictory of any given sentence and that contradictoriness is a basic notion, of which we have a grasp independent of its particular expression in some language or other. Guided by this grasp, we recognize, for example, that the contradictory of 'Some man is mortal' is 'No man is mortal'. The fundamental principle of contradictory pairs is that at least one of them must hold, but they can't both hold - and this principle is respected by the dialetheist account of negation, according to which both $\square(A \vee \neg A)$ (the law of excluded middle) and $\square \neg(A \wedge \neg A)$ (the law of non-contradiction) are true principles. Another important feature of the relation of contradictoriness is its symmetry: if $B$ is the contradictory of $A$, then $A$ is also the contradictory of $B$. This fact can be used to show that $\neg \neg A$ and $A$ are necessarily equivalent. ${ }^{12}$

The claim that the law of non-contradiction is compatible with dialetheism may surprise some readers. Is it not the fundamental thesis of dialetheism that some contradictions are true? And doesn't the law of non-contradiction rule that out by saying that all contradictions are necessarily false? The answer is yes in both cases, except that there is no rulling out and no real incompatibility. In fact, since all contradictions are necessarily false, if one of them is found to be true, it will be both true and false - i.e., it will constitute what is often called a 'dialetheia' or a

11. See Graham Priest, Doubt Truth to Be a Liar (Oxford University Press, 2006), chapters 4-6.

12. If negation forms the contradictory of any given sentence, the contradictory of $\neg A$ is $\neg \neg A$. If contradictoriness is symmetric, the contradictory of $\neg A$ is $A$. Therefore, $A$ and $\neg \neg A$ cannot fail to be equivalent.

$$
\begin{array}{ll}
\text { Vol. } 73 \\
\text { Fasc. 3-4 }
\end{array} \quad \mathbf{R P F}
$$


'truth-value glut'. This explanation, though, will inevitably leave classical logicians unsatisfied, in so far as it gives them a paradigmatic example of what they are complaining about: the extreme weakness of dialetheists' use of negation. Dialetheists assert the negation of the law of non-contradiction and, when classical logicians expect that to mean that they are denying and rejecting the law, they are instead told that dialetheists accept it as much as they do.

Dialetheists agree with classical logicians that negation reverses truth value, i.e. it turns truths into falsities and falsities into truths. More precisely: $\neg A$ is true if and only if $A$ is false and $\neg A$ is false if and only if $A$ is true. Where dialetheism deviates from the classical theory is by allowing truth and falsity to overlap - but its proponents claim that the paradoxes (semantic, set-theoretic and others) provide us with very compelling reasons to accept that. Because of that possible overlap, the truth of $\neg A$ (and that is what $A$ 's falsity is defined to consist in) does not rule out that of $A$. Hence, if we want to rule out the truth of $A$, that is, if we want to deny and reject $A$, we cannot always do it by asserting $\neg A-$ although many times we can. In non-paradoxical situations, where we can be reasonably sure that truth and falsity don't overlap, negation can safely be used to indicate denial (the speech act opposed to assertion) and to express rejection (the cognitive attitude opposed to acceptance). In and by itself, negation is really weaker than denial (in the sense that someone who asserts $\neg A$ is not thereby committed to deny $A$ ). In the great majority of cases, though, because there is no overlap of truth and falsity, asserting $\neg A$ has the same effects and carries the same commitments as denying $A$ - and that can plausibly explain why classical theorists took them to be equivalent.

According to dialetheism, then, negation and rejection, although they usually go together, can sometimes split. Denying is not the same thing as asserting a negation. A dialetheist who asserts both 'The knower sentence is known' and 'The knower sentence is not known' certainly does not want to be taken as denying the first sentence. He believes that he has proved the knower sentence. So, he believes (therefore he does not reject) that he knows it.

Human language provides us with many ways of expressing rejection. One can say, for example, 'That is wrong', 'I refuse to believe it', or one can simply shake one's head. Asserting a negated sentence can also be used to do it in many cases, but it should not always be understood as doing it. There is no clear-cut rule we can apply to tell when it does and when it does not. 


\section{Second Objection: Pragmatic Incoherence?}

I turn now to an objection addressed specifically to the dialetheist solution to the knower paradox. It claims that this solution commits dialetheists to pragmatic incoherence (a kind of irrationality), leading them to accept and reject the same thing at the same time.

Dialetheists, as we have seen above, believe they have proved, and so that they know, the knower sentence, $k$. On that basis, they accept $k$ (or that $k$ is true). A plausible general principle concerning rational acceptance is the following:

(Accept) If one accepts something, one ought to reject that one does not know it.

According to this principle, dialetheists are bound to reject that they do not know $k$, and so to reject that $k$ is not known. But, given that $k$ is ' $k$ is not known', that just is the same thing as rejecting $k$. Therefore, dialetheists are bound to reject what they, at the same time, accept (because they believe they know it, since they have been able to prove it). ${ }^{13}$

This objection poses a serious challenge to the dialetheist approach to the knower paradox, showing that new problems may arise concerning it, that did not threaten the same kind of approach to the liar paradox. However, the effectiveness of the objection is entirely dependent on the credibility of (Accept) as a correct normative principle for acceptance. I will argue, firstly, that the principle is doubtful in general, independently of dialetheism; and, secondly, that it should be rejected by someone who favours a dialetheist view of knowledge.

Let's start by considering the sources of the problem. It clearly arises because of dialetheists' different treatment of the pairs truth/falsity and acceptance/rejection. While thinking that truth and falsity can sometimes overlap and that, when they do, a sentence and its negation are both true, so that it is right to assert them both, on the other hand, dialetheists assume - correctly, I believe - that one cannot accept (the content of) a sentence and reject it at the same time. On their view, whereas truth and falsity are exhaustive but not exclusive, acceptance and rejection are exclusive but not exhaustive. It is never rational to accept and reject the same thing at the same time, although sometimes one can be justified in

13. This objection was raised by Elia Zardini at a LanCog research seminar (in October of 2016) in the University of Lisbon.

$$
\begin{aligned}
& \text { vol. } 73 \text { forc. 3-4 } \\
& \text { RPF } 2017
\end{aligned}
$$


doing neither of them, but suspend judgement instead - if, for example, one has not enough evidence for its truth or untruth.

While assertion and denial are speech acts, acceptance and rejection are cognitive attitudes. They are very closely tied to each other, since typically by (sincerely) asserting a sentence one expresses one's acceptance of its content and by (sincerely) denying it one expresses one's rejection of its content. Being cognitive attitudes, acceptance and rejection are also tied to belief and knowledge. Putting aside the issue of degrees of belief (because it's not relevant to the present discussion, where only full beliefs are involved), we can say that to accept something is simply to believe it - or, as Priest likes to say, to put it in one's belief box ${ }^{14}$. What about rejection? Rejecting something is a positive attitude, involving much more than merely not accepting it - it requires a refusal to believe it, a decision to keep it out of the belief box (at least in the case of conscious rejections). The connection these attitudes have with knowledge is much less clear and it has been a subject of controversy since ancient times. The Stoics thought that one should accept only what one knows and some Sceptics agreed with them, while adding that nothing is known. ${ }^{15}$ Many people take this requirement to be too demanding. It seems quite natural to assume that often we can have enough evidence to be justified in accepting something without that evidence being sufficient to provide knowledge. In some cases, it seems even right to accept something that, unbeknownst to us, turns out to be false. Some people may want to dispute this, though. In the contemporary debate on the norms of assertion, many philosophers have defended the so-called knowledge account of assertion, according to which one should assert only what one knows - and some may find attractive the idea of extending that account to apply it to belief as well. ${ }^{16}$

14. See Priest, Doubt Truth to be a Liar, 103.

15. Cicero tells us that both Zeno of Citium and Arcesilaus maintained that it is a mark of wisdom not to hold opinions' (Acad. 2. 77). Arcesilaus, 'considered it particularly rash to approve something false or unknown, because nothing was more shameful than for one's assent or approval to outrun knowledge' (Acad. 1. 44). See Cicero, On Academic Scepticism, trans. Charles Brittain (Indianapolis: Hackett, 2006), 45 and 106.

16. See Timothy Williamson, Knowledge and its Limits (Oxford University Press, 2000), 238-269, for a very influential defense of the knowledge account of assertion; and the essays in Jessica Brown and Herman Cappelen, eds., Assertion: New Philosophical Essays (Oxford University Press, 2011), for discussion and alternative accounts. Jonathan Adler, Belief's Own Ethics (Cambridge, Mass. and London: MIT Press, 2002), Jonathan Sutton, Without Justification (Cambridge, Mass. and London: MIT Press, 2007) and John Gibbons, The Norm of Belief (Oxford University Press, 2013) all say that knowledge is the norm of belief.

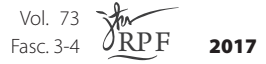


Given that the connection between accepting and knowing is so uncertain and controversial, what should we think of (Accept)? It states a principle of coordination between acceptance and rejection. In general, some pairs of contents are related in such a way that, if one accepts one of them, one is rationally bound to reject the other. For instance, if someone accepts that Lisbon is north of Évora, one has to reject that Évora is north of Lisbon. Classical logicians take negation to create just such pairs: on their view, in general, if one accepts $\neg A$, one must reject $A$. Dialetheists deny that negation always works this way, although they admit that it does in many cases. For example, Priest would agree that, if one accepts that truth is inconsistent, one should reject that truth is consistent. However, he would disagree with someone who claimed that if one accepts that the liar sentence is not truth, one is committed to reject that the liar sentence is true. It should be noticed, though, that what (Accept) purports to give us is not, as in the previous examples, a strong incompatibility between two contents, but rather an incompatibility between one content and the acceptance of another.

One way to try to justify (Accept) is by considering the epistemic version of Moore's paradox, in which someone accepts something of the form:

It is snowing outside, but I do not know that it is.

Why is that absurd, given that it could so easily be true? Some epistemologists have proposed an explanation based on the idea that knowledge, and not just truth, is the aim of belief and therefore believing something implies the claim to know it. ${ }^{17}$ According to this view, when an honest and responsible thinker believes something he is under the obligation to evaluate positively his own belief. So he is required to have a metabelief to the effect that his first belief is epistemically acceptable, that it meets appropriate epistemic standards. And, it is claimed, for any condition $C$ necessary for knowledge, if one realizes that a belief does not satisfy $C$, that gives sufficient reason to consider that one should not hold that belief. Thus a belief is seen as epistemically acceptable only if it is believed

17. See David Owens, Reason Without Freedom: The Problem of Epistemic Normativity (London and New York: Routledge, 2000) and Michael Huemer, "Moore's Paradox and the Norm of Belief," in Themes From G. E. Moore: New Essays in Epistemology and Ethics, eds. Susana Nuccetelli and Gary Seay (Oxford: Clarendon Press, 2007), 142-157.

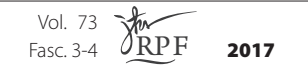


to satisfy every condition necessary for knowledge. Therefore, a belief that $p$ would imply the belief that one knows that $p$ - and that would explain why the assertion of Moorean sentences of the form ' $p$, but I do not know that $p$ ' has the appearance of being self-contradictory: by accepting the first conjunct, one would be committed to believing that one knows that $p$; by accepting the second conjunct, one would be compromising that commitment. Finally, this explanation of the absurdity of Moorean sentences would also provide a justification for the principle (Accept), on the following lines: if one accepts $p$, one should also accept that one knows that $p$; therefore, one should reject that one does not know that $p$.

However, the requirement that one should believe that $p$ only if one believes that one knows that $p$ is untenable, because it entails that one should believe that $p$ only if one believes that one knows that one knows that one knows ... (indefinitely many times) that $p$ - and that is obviously unrealistic. In fact, to require that a responsible thinker should evaluate positively and have a cognitive meta-attitude concerning every belief he holds is clearly too demanding. Many of our actual beliefs are held unconsciously. We are not aware of having them, so a fortiori we do not appraise them in any way. As Huemer notes:

A subject believing that $p$ might simply fail to consider whether his belief that $p$ is epistemically acceptable; this would not render the subject irrational. ${ }^{18}$

\section{And Littlejohn agrees:}

It is simply not true that if you permissibly believe $p$, you ought to believe that your belief satisfies a comprehensive epistemic endorsement. Failing to have any belief about whether you know $p$ when you happen to believe $p$ (and happen not to be wrong to do so) is no sin at all. ${ }^{19}$

This fact seems to tell against the principle that belief implies the claim to know, and also against (Accept) as a correct epistemic norm. Rationality does not demand that we take a position on whether we know something whenever we believe it: it does not require that we accept that we know and it does not require that we reject that we do not know. What rationality requires is rather that, if we come to believe that we do not know something

18. Huemer, "Moore's Paradox," 148.

19. Clayton Littlejohn, "Moore's Paradox and Epistemic Norms," Australasian Journal of Philosophy 88, no. 1 (2010): 93.

$$
\begin{aligned}
& \text { Vol. } 73 \\
& \text { Fasc. 3-4 热 }
\end{aligned}
$$


(for example, because we realize that we do not have sufficient evidence for it, or simply because it is false), we ought to withdraw our belief in it, if we had it. It is epistemically unacceptable to believe both $p$ and that we do not know that $p$ - and that is enough to explain, in normative terms, the absurdity of Moorean utterances. But the requirement is a weaker one: it just says that one should believe that $p$ only if one does not believe that one does not know that $p$. Since rejecting is more than not accepting, this requirement, although explaining the epistemic version of Moore's paradox, does not justify (Accept).

One obvious reaction would at this point be: even if you're right that (Accept) does not hold in full generality, it obviously holds in cases like the one we are considering here, where someone accepts something because he has been able to prove it. The grounds for taking exception with (Accept) - viz., that one can be unaware of accepting something or fail to consider whether one knows it - are clearly absent in the present case. Therefore, the principle applies and the objection stands.

The decisive reply has to appeal to the dialetheist view of knowledge and it is very straightforward. Someone who thinks that knowledge is inconsistent - that is, to use Beall's construal of that claim, that 'the full description of human knowledge includes "It is known that $p$ " and "It is not known that $p$ ", for some $p^{20}$ - has sufficient reason to deny the principle (Accept) when it comes to cases of possible inconsistent knowledge. If a true proposition can be such that it is possible that one both knows and does not know it at the same time, the norms of rationality have to conform to that possibility, hence they cannot require the reflective thinker to reject 'I do not know that $p$ ' whenever he accepts $p$ - in fact, they should allow him to jointly accept both. Surprisingly as it may be, if knowledge is inconsistent, not all Moorean utterances of the form ' $p$ and I do not know that $p^{\prime}$ are irrational.

The original and standard version of Moore's paradox is with belief. There is an omissive form - ' $p$, but I don't believe that $p$ ' - and a comissive form - ' $p$, but I believe that not- $p$ '. Both are generally taken to be absurd and irrational. However, if one endorses very radical philosophical views, one can find oneself in a position to reasonably assert sentences of those very forms. Turri ${ }^{21}$ gives an example of an eliminativist about propositional attitudes who holds that there are no mental states such as beliefs. Against

20. Beall, “Fitch's Proof," 243.

21. See John Turri, "Refutation by Elimination," Analysis 70, no. 1 (2010): 35-39.

$$
\begin{aligned}
& \text { vol. } 73 \text { jtor } \\
& \text { Fasc. 3-4 RPF } 2017
\end{aligned}
$$


that background, her assertion of 'It is snowing, but I don't believe that it is' is reasonable enough. Williams ${ }^{22}$ gives another example of a dialetheist who holds that some contradictions are true. Against that background, her assertion of 'The liar sentence is true, but I believe that it is not true' is again reasonable enough. We should now add one more example, of a dialetheist who holds that knowledge is inconsistent. Against that background, her assertion of 'The knower sentence is not known and I do not know that the knower sentence is not known ${ }^{\prime 23}$ is no less reasonable than those of the previous examples. One may not be persuaded by dialetheism and by its approach to the knower paradox, but if someone accepts it and accepts the paradox as a sound argument, it is to be expected that she will revise and weaken the rational commitments that come with that acceptance.

My claim is that the objection against the dialetheist solution to the knower paradox fails, because it relies on an epistemic norm that dialetheists should not accept. True propositions, according to them, come in three categories: (i) those that one only knows, (ii) those that one only does not know and (iii) those that one both knows and does not know. Dialetheists can agree that, if one accepts a proposition and considers whether one knows it, one has to reject that it belongs to the second category - but no more than that.

\section{Third Objection: the Scope of Inconsistent Knowledge}

The third and final objection I will consider is addressed to the dialetheist approach to Fitch's paradox of knowability that Beall and Priest have proposed. It concerns the scope of inconsistent knowledge and it claims that, even assuming that there is a proposition - namely, the one expressed by the knower sentence - concerning which knowledge is inconsistent, we have been given no reason to think that knowledge can be inconsistent concerning every truth that is actually unknown. ${ }^{24}$

Accepting the argument of the knower paradox with its conclusion, as dialetheism recommends, surely dispels any worry one might have had about the general possibility of inconsistent knowledge. Fitch's argument,

22. See John N Williams, "Eliminativism, Dialetheism and Moore's Paradox," Theoria 81, no. 1 (2015): 27-47.

23. Or, equivalently: 'The knower sentence is true, but I do not know it'.

24. This objection is raised in Beall, "Fitch's Proof," 246.

$$
\begin{aligned}
& \text { Vol. } 73 \\
& \text { Fasc. 3-4 你 }
\end{aligned}
$$


once it has been recast in a paraconsistent framework, shows that, for some propositions, it is possible that they are both known and unknown and the knower paradox arguably proves something which implies that possibility. It would seem, then, that dialetheists are justified in accepting the conclusions of both arguments - and there lies the solution to both problems. However, on a closer inspection, one can see that Fitch's argument shows much more: namely, that the knowability principle implies that inconsistent knowledge is possible for every actually unknown truth. But why should non-knowledge be always tied to possible inconsistency (of knowledge)? By showing that the knowability principle has this weird consequence, Fitch's argument can still give us a strong reason to reject the principle - even if it is not an undisputable proof of its untruth, as it was often thought to be.

Unlike the previous ones, this objection seems to me rightly made and without any good reply. To minimize its effect, dialetheists could try to find evidence for there being more cases of possible inconsistent knowledge, involving other unknown truths besides the knower sentence. Priest attempted to do so. He described a possible situation in which, for a specific agent, every truth is knowable, but plenty of truths remain unknown. It is a situation involving just two persons: one omniscient being, God, and his close friend, Gabriel, who does not know lots of things, but could know all of them, just by asking God. Let's suppose, for example, that Gabriel does not know (at any time) how far Évora is from Lisbon. He is an admirer of both cities, but that question never crossed his mind, so he never asked. There is then a true proposition about that distance $(g)$, which is such that Gabriel does not know it $(\neg K g)$, although he could know it $(\nabla K g)$. Since Gabriel does not know $g$, there is also a true complex proposition, $g \wedge \neg K g$, which we can call $m$ (to remind us of its quasi-Moorean syntactic form). If every truth is knowable, this one in particular has to be knowable also: $\diamond K m$, that is, $\diamond K(g \wedge \neg K g)$. Fitch's argument shows that $\diamond K(g \wedge \neg K g)$ implies $\diamond(K g \wedge \neg K g)$ : it being knowable that $g$ is an unknown truth implies it being possible that $g$ is both known and unknown. However, Priest has no plausible explanation to give for this last possibility.

Assuming that Gabriel does not know $g$, it follows that he also does not know the conjunction $g \wedge \neg K g$, i.e. $m$. But God knows it. And Gabriel knows that God knows everything. Could Gabriel know $m$ ? Priest sees the situation as follows: 
... could [Gabriel] not ask God whether $m$ is true, and get an answer? Of course he could. If, as we suppose, $m$ is true, God will tell him so. Hence, Gabriel will know $g$, and $m$ is false. Suppose, on the other hand, that $m$ is false. Then God will tell him so. At this point Gabriel still does not know whether $g$ is true or false. Suppose we then shoot him; he never will. So $m$ is true.

None of this shows that Gabriel cannot know m; all it shows is that, if he does ask the question, the situation is a paradoxical one. ${ }^{25}$

Priest's reasoning here seems to be misguided. How could Gabriel come to know $g$ upon being informed by God that $m$ is true? Of course, in general, if God tells anyone that a conjunction is true, that person comes to know it and, seeing that it implies the first conjunct, also comes to know the first conjunct. But in this special case we are reasoning under the supposition that $g$ is true and Gabriel does not know it at any time (past, present or future). If Gabriel does not know $g$ at any time, then he also does not know $m$ at any time (by a contraposed form of the principle that knowledge distributes over conjunction). If Gabriel does not know $m$ at any time, then God does not tell him that $m$ is true (by a contraposed form of the implicit assumption that God's answers transmit knowledge). If God does not tell Gabriel that $m$ is true, then Gabriel does not ask him whether $m$ is true (by a contraposed form of the implicit assumption that God answers every question that Gabriel asks). We have just established that, given our implicit assumptions, if Gabriel does not know $g$ (at any time), he does not ask God (at any time) whether $m$ is true. But could Gabriel ask God and thereby come to know $m$ ? This last question leads us to consider another (accessible) world. If what we want to figure out is whether $m$ is known in that other world, we'd better make $m$ true there too - but once we do that, we determine (if our implicit assumptions are kept fixed, as they should) that Gabriel does not ask. So there is simply no world in which Gabriel knows $m$, and this indeed shows that he cannot know $m .^{26}$

25. Priest, "Beyond the Limits of Knowledge," 101. I have adapted the nomenclature.

26. It is hard to see what role does Priest's supposition that $m$ is false could play in the argument. Is there a world in which Gabriel knows $m$ despite it being false? Only if $m$ is also true there. And in fact that seems to be what Priest is after: a world in which $m$ is a dialetheia. But it does not seem to help him much, for two reasons. Firstly, the reasoning is fallacious. From Gabriel's untimely death one cannot infer that $g$ is not known (at any time). Maybe $g$ is true and Gabriel knew it some years ago, without now knowing that he knew it: his death prevents him from ever knowing that he once had that piece of knowledge, but it does not prevent $g$ from being known (because it

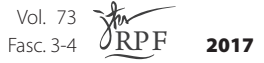


So the objection still stands. Even assuming, with the dialetheists, that there is inconsistent knowledge in the case of the knower sentence, Fitch's argument reveals something odd about the unrestricted principle of knowability: if the principle were true, every case of ignorance would be also a case of possible inconsistent knowledge. Since we have no evidence for this being so, Fitch's argument keeps much of its force against that principle.

\section{Conclusion}

I conclude that the unified solution to the knower paradox and to Fitch's paradox of knowability recently proposed by dialetheists fails. The dialetheist approach to the knower paradox is indeed a serious candidate, withstanding the main objections against it. As regards Fitch's paradox, we have seen that in its original form it is not paraconsistently valid. But there is a valid recast of the argument in a paraconsistent framework, showing that if the principle of knowability were true, every actually unknown truth would be a case of possible inconsistent knowledge. The knower sentence is, for dialetheists, precisely one such case: a truth that is both known and not known. Dialetheists, however, have not been able to provide evidence for other interesting cases - and even less for there being a general correspondence between unknown truth and possible inconsistent knowledge. That being so, Fitch's argument still stands as a serious problem for supporters of the principle of knowability. ${ }^{27}$

already was). Secondly, and most importantly, even if the reasoning were correct (perhaps because everything that is known is known to be known), it would turn out to be a world in which $m$ is not known - and so it would be useless as a means to show that $m$ is knowable.

27. Earlier versions of this work have been presented at the LanCog Friday Seminar (University of Lisbon) and at a workshop on 'Thought, Object and Language' in Curitiba (Federal University of Paraná). For the stimulating discussions and useful feedback, which led to significant improvements, I am grateful to the audiences on both occasions. Special thanks to Breno Hax Junior, Célia Teixeira, David Yates, Desidério Murcho, Diogo Santos, Domingos Faria, Elia Zardini, Elton Marques, Fernando Furtado, Guido Imaguire, Hili Razinski, Hugo Luzio, José Manuel Mestre, Laura Delgado, Luís Veríssimo, Pedro Dinis, Ricardo Miguel and two anonymous referees.

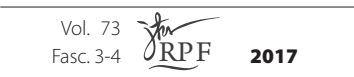




\section{References}

Adler, Jonathan. Belief's Own Ethics. Cambridge, Mass. and London: MIT Press, 2002.

Beall, JC. "Fitch's Proof, Verificationism, and the Knower Paradox." Australasian Journal of Philosophy 78, no. 2 (2000): 241-247.

Brown, Jessica, and Herman Cappelen, eds. Assertion: New Philosophical Essays. Oxford University Press, 2011. Cicero. On Academic Scepticism. Translated by Charles Brittain. Indianapolis: Hackett, 2006.

Fitch, Frederic. “A Logical Analysis of Some Value Concepts.” Journal of Symbolic Logic 28, no. 2 (1963): 135-142. Gibbons, John. The Norm of Belief. Oxford University Press, 2013.

Huemer, Michael. "Moore's Paradox and the Norm of Belief." In Themes From G. E. Moore: New Essays in Epistemology and Ethics, edited by Susana Nuccetelli and Gary Seay, 142-157. Oxford: Clarendon Press, 2007.

Kaplan, David and Richard Montague, “A Paradox Regained.” Notre Dame Journal of Formal Logic 1, no. 3 (1960): 79-90.

Littlejohn, Clayton. "Moore's Paradox and Epistemic Norms." Australasian Journal of Philosophy 88, no. 1 (2010): 79-100.

Owens, David. Reason Without Freedom: The Problem of Epistemic Normativity. London and New York: Routledge, 2000.

Priest, Graham. Beyond the Limits of Thought. Oxford: Clarendon Press, 2002.

Priest, Graham. Doubt Truth to Be a Liar. Oxford University Press, 2006.

Priest, Graham. An Introduction to Non-Classical Logic (2 $2^{\text {nd }}$ edition). Cambridge University Press, 2008.

Priest, Graham. "Beyond the Limits of Knowledge." In New Essays on the Knowability Paradox, edited by Joe Salerno, 93-104. Oxford University Press, 2009.

Routley, Richard. "Necessary Limits to Knowledge: Unknowable Truths." In Essays in Scientific Philosophy. Dedicated to Paul Weingartner, edited by M. Edgar, N. Otto and Z. Gerhard, 93-115. Bad Reichenhall: Comes Verlag, 1981.

Salerno, Joe. 2009. "Knowability Noir: 1945-1963.” In New Essays on the Knowability Paradox, edited by Joe Salerno, 29-48. Oxford University Press, 2009.

Sutton, Jonathan. Without Justification. Cambridge, Mass. and London: MIT Press, 2007.

Turri, John. "Refutation by Elimination." Analysis 70, no. 1 (2010): 35-39.

Williams, John N. “Eliminativism, Dialetheism and Moore's Paradox.” Theoria 81, no. 1 (2015): 27-47.

Williamson, Timothy. Knowledge and its Limits. Oxford University Press, 2000. 